\title{
AS PRÁTICAS ITINERANTES DE CUIDADO NO CONTEXTO DA SAÚDE MENTAL NO BRASIL
}

\author{
Emile Costa Santos*, Fábio Giorgio Santos Azevedo** \\ Autor correspondente: Emile Costa Santos - emilepsi@gmail.com \\ * Psicóloga pela Escola Bahiana de Medicina e Saúde Pública. \\ ** Psicólogo graduado pela Universidade Federal da Bahia (UFBA). Especialista em Antropologia Visual (UFBA) e Mestre \\ em Educação (UFBA). Professor nas universidades Católica do Salvador (UCSAL) e Salgado de Oliveira, e na Escola \\ Bahiana de Medicina e Saúde Pública (EBMSP).
}

\begin{abstract}
Resumo
O processo da Reforma Psiquiátrica no Brasil desencadeou mudanças nas formas de atenção em saúde mental. Foram criadas novas tecnologias de cuidado, buscando uma aproximação com o território de vida dos usuários. Este estudo tem como objetivo problematizar os alcances, as repercussões e as bases teórico-metodológicas das práticas de cuidado itinerantes em saúde mental desenvolvidas no Brasil, após a reforma psiquiátrica. O objetivo geral do estudo foi conhecer as práticas de cuidado itinerantes em saúde mental desenvolvidas no Brasil, após o início do processo de Reforma Psiquiátrica. Os objetivos específicos foram identificar as bases teórico-metodológicas das práticas itinerantes em saúde mental e investigar suas repercussões. Por meio de uma revisão de literatura, foi possível conhecer materiais publicados sobre a temática, identificando relações e limitações de práticas que tomam o território e o movimento como elementos para a construção de um cuidado singular. Foram utilizados livros e as bases de dados bibliográficos Literatura Latino Americana e do Caribe em Ciência da Saúde (LILACS) e Scientific Electronic Library Online (SciELO). Os descritores escolhidos foram "práticas"; "território"; "saúde mental" e "cuidado". Foram selecionados para o desenvolvimento do trabalho aqueles com correspondência ao tema "Práticas itinerantes em saúde mental", segundo indicação do resumo ou palavras-chave, que estavam disponíveis em português, com período de publicação igual ou superior a 2009. Concluiu-se que as práticas de cuidado itinerantes teriam potencial de gerar transformações em todos os agentes envolvidos, contemplar grupos populacionais historicamente excluídos e garantir o território de vida como estratégia de promoção da saúde.
\end{abstract}

Palavras-chave: Práticas; Território; Saúde Mental; Cuidado. 


\title{
ITINERANT PRACTICE CARE IN THE CONTEXT OF MENTAL HEALTH IN BRAZIL
}

\begin{abstract}
The process of Psychiatric Reform in Brazil triggered changes in the forms of mental health care. New care technologies were created, seeking an approach to the territory of life of users. This study aimed to discuss the reaches, the effects and the theoretical and methodological bases of itinerant care practices in mental health developed in Brazil, after the psychiatric reform. The general objective of the study was to know the itinerant care practices in mental health developed in Brazil, after the beginning of psychiatric reform process. The specific objectives were to identify the theoretical and methodological bases of itinerant practices in mental health and investigate its repercussions. Through a literature review, it was possible to know published materials on the subject, identifying relations and limitations of practices that take the territory and movement as elements for the construction of a singular care. Books and bibliographic databases Latin American and Caribbean Literature in Health Sciences (LILACS) and Scientific Electronic Library Online (SciELO) were used. The chosen descriptors were "practical"; "territory"; "Mental health" and "care". Were selected for the development of work those matching the theme "traveling practices in mental health," according to statement of the abstract or keywords, which were available in Portuguese, with publication period greater than or equal to 2009. It is concluded that the itinerant care practices have the potential to generate transformations in all the agents involved, contemplate population groups historically excluded, and to ensure the territory of life as a health promotion strategy.
\end{abstract}

Keywords: Practices; Territory; Mental health; Care.

\section{INTRODUÇÃO}

$O$ interesse pelo tema surge com uma pesquisa abrangente sobre o desenvolvimento de tecnologias do cuidado que divergissem das práticas tradicionais do campo da Saúde Mental, e da leitura do livro "Clínica Peripatética", de Antonio Lancetti, ${ }^{(1)}$ que abriu novos territórios para a criação dos objetivos traçados nesse trabalho. As práticas itinerantes apontaram para um exercício que estaria de acordo com a desinstitucionalização e com outros princípios da Reforma Psiquiátrica. As discussões sobre estas práticas são atravessadas por noções sobre cuidado, território e políticas públicas, envol- vendo também reflexões sobre a garantia do acesso integral aos serviços de atenção em saúde.

Para a elaboração do presente trabalho, realizou-se um estudo qualitativo, por meio de uma revisão de literatura. Como ferramentas de busca foram utilizadas as bases de dados bibliográficos Literatura Latino Americana e do Caribe em Ciência da Saúde (LILACS), Scientific Electronic Library Online (SciELO). Os descritores escolhidos foram: "Práticas", "Território", "Saúde Mental" e "Cuidado", obtendo-se através deles 191 artigos no período entre novembro de 2014 a novembro de 2015 . 
Selecionou-se para o desenvolvimento do trabalho estudos que corresponderam ao tema "Práticas itinerantes em saúde mental", segundo indicação do resumo ou palavras-chave, que estavam disponíveis em português, com período de publicação igual ou superior a 2009. Foram selecionados 20 artigos e, também, 5 livros, leis e documentos oficiais para dar corpo ao texto. Excluiu-se artigos com conteúdo repetido ou sem fundamentação teórica.

A escolha pela realização de uma pesquisa exploratória decorreu do fato de que esta, por conta de suas características, levaria a uma aproximação com o tema proposto, proporcionando uma visão geral sobre ele. Através dela, buscou-se desenvolver e esclarecer conceitos e ideias que podem ser melhor delimitados em estudos posteriores, através de processos mais sistematizados. (2) Segundo Gil, (2) a pesquisa bibliográfica se desenvolve principalmente através do uso de livros e artigos científicos publicados, permitindo ao pesquisador a aproximação com uma gama de fenômenos mais ampla do que aquela que poderia ser pesquisada diretamente, tornando possível a coleta de informações sobre estas práticas, abordando diferentes aspectos.

Através da análise da literatura investigada, foi possível elaborar duas categorias para nortear a discussão realizada no estudo, são elas: As Tecnologias Itinerantes de Cuidado e Repercussões e Articulações entre as Práticas Itinerantes e as Políticas de Saúde.

A pesquisa sobre as práticas de cuidado itinerantes em Saúde Mental no Brasil se justifica por sua importância estratégica para o alcance da integralidade, da desinstitucionalização e da reinserção social, almejos da Reforma Psiquiátrica e da Reforma Sanitária. (3) Tendo em vista que muitos protocolos clínicos tradicionais revelam-se ligados ao sistema manicomial excludente e gerador de cronificações, e a complexidade da dimensão do cuidado em Saúde Mental se faz necessário refletir sobre os lugares e os movimentos da clínica. A itinerância em saúde mental se apresenta como uma alternativa singular de cuidado que seria capaz de gerar no- vas repercussões, como por exemplo, conectar os usuários a atividades, pessoas e locais, dando corpo à "produção desejante". ${ }^{(1,4)}$

A saúde mental é um campo complexo de conhecimento e de atuação, que sofre mudanças a depender das condições histórico-culturais do momento em que se discute. ${ }^{(5)}$ Aos poucos, as conceituações ligadas à psiquiatria tradicional, centradas na doença, estão sendo substituídas por outras, que têm como objetivo a promoção de saúde mental. Este processo teria sido provocado por debates sobre a legitimidade das práticas deste campo, bem como os saberes e os discursos que as fundamentam. Paulo Amarante ${ }^{(6)}$ traça um percurso histórico sobre o alienismo, a primeira ciência a se debruçar sobre a loucura, destacando o surgimento do Hospital Geral, na França, que substitui os hospitais filantrópicos e passam a enclausurar os loucos, principalmente por determinação das autoridades no século XVII.

No século XVIII, Pinel propõe que os loucos sejam libertados das correntes. Mas para que fiquem livres de sua loucura, devem permanecer isolados. Dessa forma, foi possível consolidar a criação do alienismo e a prática do isolamento como principal medida de tratamento. No Brasil do século XX o alienismo foi mantido como forma de tratamento e tem na figura de João Pinheiro Silva, um representante que pretendia educar a mente como medida para livrá-la da loucura. ${ }^{(6)} \mathrm{Na}$ tentativa de reformular as práticas psiquiátricas foram criadas as colônias terapêuticas, que no Brasil eclodiram após a Proclamação da República. Com o passar do tempo, as colônias terapêuticas mostraram reproduzir as práticas asilares e por isso receberam críticas que possibilitaram a criação de movimentos em vários países, em prol de mudanças nas formas de tratar a loucura. ${ }^{(6)}$

A promulgação da nova Constituição Federal, em 1988, marca o retorno do Brasil ao regime democrático e estabelece que a saúde é um direito universal. (7) A busca por ampliação dos serviços, influenciada pela ideia de planejamento, coordenação e avaliação de ações especializadas, a busca 
pela integração entre cura e prevenção vivenciadas a partir da década de 70, somadas à ideia de um estado de bem-estar social geraram críticas e pautas que deram início ao processo de Reforma Sanitária no Brasil, que tinha a pretensão de propagar a concepção do direito à saúde como um aspecto da cidadania. ${ }^{(7)}$

A oitava Conferência Nacional de Saúde (1986), um marco da Reforma Sanitária, contou com pautas relativas à reforma do sistema nacional de saúde e a oferta do direito à saúde como dever do Estado, o que abriu portas para a aprovação do SUS e a consolidação dos seus princípios de equidade, integralidade e universalidade. ${ }^{(7)}$

Desde a criação do SUS ampliou-se a busca por uma aproximação com o território, que passa a ser visto como o espaço onde se organiza uma rede de serviços com o objetivo de assegurar a universalidade, a equidade e a integralidade do cuidado em saúde. ${ }^{(3)} \mathrm{O}$ processo de territorialização teria como objetivo a organização das ações para a garantia do acesso da população aos serviços de saúde.

Outro movimento de ampla repercussão no campo da saúde é o processo de Reforma Psiquiátrica no Brasil. Tendo início na década de 70 , a Reforma Psiquiátrica estava relacionada à "psiquiatria de setor" criada na França, que priorizaria a assistência ao paciente em sua própria comunidade; a "psiquiatria preventiva" ou "comunitária", que teria como foco a busca pela causa e a prevenção da doença mental; a "antipsiquiatria", surgida na década de 60 na Inglaterra e a "psiquiatria democrática" italiana que propunha a desconstrução manicomial. ${ }^{(5)}$

$\mathrm{Na}$ trajetória da Reforma Psiquiátrica brasileira destaca-se a crise na Divisão Nacional de Saúde Mental, provocada pelas condições precárias de trabalho e denúncias de irregularidades no tratamento em unidades do DINSAM no Rio de Janeiro; o nascimento do Movimento dos Trabalhadores em Saúde Mental (MTSM), que incluiu profissionais de diversas categorias para promover discussões sobre a assistência psiquiátrica e lutar por transformações no campo; a I Conferência Nacio- nal de Saúde Mental, que referenciou o surgimento de novas formas de cuidado como alternativa possível ao atendimento psiquiátrico tradicional; a criação do CAPS (Centro de Atenção Psicossocial) Professor Luiz da Rocha Cerqueira em 1987 na cidade de São Paulo, incentivando o surgimento de outros serviços no país e a intervenção e fechamento, pela Secretaria de Saúde de Santos, da Casa de Saúde Anchieta, um hospital privado onde se comprovou casos de crueldade e morte de internos. ${ }^{(5)}$

O desejo por uma forma preventiva de cuidado que envolvesse a participação da comunidade provocou mudanças no contexto da psiquiatria tradicional, que teve como características o reducionismo (evidente em práticas em que se busca meramente eliminar o sintoma), a normalização e a classificação. Essas aspirações provocaram transformações em hospitais psiquiátricos e a implantação de dispositivos como hospitais-dia, CAPS e NAPS (Núcleo de Atenção Psicossocial) e junto a essas mudanças têm surgido novas experiências conectadas aos contextos onde ocorrem. ${ }^{(5)}$

\section{DISCUSSÃO}

As práticas itinerantes são uma forma de tecnologia do cuidado desenvolvidas no território em que os usuários vivem e constroem relações. ${ }^{(3)}$ Acredita-se que através dessa intervenção, seja possível promover uma forma contextualizada de atenção, ligada a realidade de vida dos usuários, garantindo o seu pertencimento ao território, que passa a ser entendido como o lugar em que se constroem relações e modos de existência. ${ }^{(3)}$

Diversas formas de práticas itinerantes são citadas na literatura. Elas reúnem aspectos convergentes, entre eles a visão sobre o território como espaço de realização de práticas de cuidado e ações de saúde, e aspectos singulares que preservam suas especificidades. Segundo Lemke e Silva, ${ }^{(8)}$ o Acompanhamento Terapêutico, o trabalho dos Agentes Comunitários de Saúde e o Consultório de Rua são tecnologias que tem em comum o exercício em 
movimento e a realização de ações no território de vida dos usuários, próximo ao seu cotidiano.

Lemke e Silva(3) trazem um panorama das denominações de práticas que são realizadas através da itinerância, dando destaque a termos como "clínica itinerante", que dá ênfase ao manejo clínico realizado no Acompanhamento Terapêutico, que segundo Reis Neto, Pinto e Oliveira ${ }^{(9)}$ refere-se à condução do vínculo e da escuta realizada pelo Acompanhamento Terapêutico (AT).

Ao referir-se ao trabalho dos acompanhantes terapêuticos, Palombini (2004) utiliza o termo "Clínica em movimento", Silva (2005) utiliza a expressão "Fazer Andarilho" (2005) e Petuco e Medeiros (2008) escolhem a expressão "clínica aberta" para fazer referência a esta mesma prática. ${ }^{(3)}$

A clínica peripatética foi enunciada por Araujo (2006), fazendo referência às práticas de cuidado que são operadas através do deslocamento no território do usuário. ${ }^{3}$ Lancetti' utiliza este mesmo termo, fazendo referência à escola filosófica criada por Aristóteles, onde se costumava ensinar caminhando pelos jardins de Apolo no Liceu e a leituras psicanalíticas que tratam da prática de Freud de realizar sessões caminhando ao ar livre. Este segundo autor também utiliza o termo práxis peripatética e clínica cartográfica para se remeter às práticas que possuem um "setting móvel", produzindo o que também chamou de "clínica arqueológica".(3)

Entre os 191 artigos encontrados nesta pesquisa, 154 discutiam o Acompanhamento Terapêutico como prática itinerante, 4 trouxeram debates sobre o Consultório de/na Rua e apenas os estudos de Lemke e Lemke e Silva articulavam essas duas tecnologias do cuidado ao trabalho dos Agentes Comunitários de Saúde, confirmando seu potencial para atenção em Saúde Mental. A discrepância entre as produções que tratam sobre estas três práticas evidenciou que tanto o Consultório de/na Rua quanto o trabalho dos Agentes Comunitários de Saúde necessitam de mais publicações que discutam e confirmem o seu papel enquanto prática de cuidado.

\subsection{AS TECNOLOGIAS ITINERANTES DE CUIDADO}

O Acompanhamento Terapêutico (AT) é uma prática itinerante e como tal, é realizada fora dos espaços típicos de atendimento à saúde, como hospitais e consultórios. O AT é caracterizado, essencialmente, pelo movimento que faz em sua realização e pela ausência de espaços fixos de atuação, privilegiando a utilização de espaços abertos para a formação de vínculo entre o usuário e o território. ${ }^{(9,4)}$

Inicialmente exercido como forma de substituir à internação, o Acompanhamento Terapêutico passou a se destacar pelo uso da escuta clínica e do manejo do vínculo como instrumentos de trabaIho. ${ }^{(9)}$ Segundo Lemke ${ }^{(4)}$ a prática do AT teve início no trabalho dos atendentes psiquiátricos das Comunidades Terapêuticas, surgidas na década de 60 inspiradas em experiências que, desde a década de 50 estabeleciam críticas ao modelo manicomial que já era entendido como impróprio.

O AT se realizaria através de deslocamentos em espaços públicos e familiares, onde é possível atuar ofertando a escuta no momento em que acontecem produções como delírios e alucinações. Dessa forma, se tem acesso direto às conexões entre as produções subjetivas e os lugares e situações em que se desencadeiam. ${ }^{(9)} \mathrm{O}$ Acompanhamento Terapêutico, assim como as outras práticas itinerantes, oferece condições de cuidado que podem ser melhor suportadas por sujeitos que muitas vezes são avessos às formas tradicionais de atenção em saúde mental.

Segundo Reis Neto, Pinto e Oliveira ${ }^{(9)}$ o público principal do Acompanhamento Terapêutico é formado por pacientes com transtornos mentais ou em sofrimento psíquico que

\footnotetext{
"por razões variadas requerem mais (ou menos) do que oferecem os espaços tradicionalmente destinados ao seu tratamento". Usuários que mesmo fora dos espaços de internação, ficam confinados em suas casas restringindo seus laços sociais. A presença do AT oferece a perspectiva de troca para alguém que se retrai". ${ }^{(9: 31)}$
} 
O Acompanhamento Terapêutico inicialmente era solicitado por psiquiatras como forma de substituir a internação visto que, através de seu trabaIho, o acompanhante é capaz de realizar a contensão simbólica de conteúdos que poderiam levar o usuário ao confinamento em instituições psiquiátricas. (9) Com o passar do tempo, o AT passou a ser reconhecido como um trabalho que traz em si a especificidade de oferecer a escuta clínica no deslocamento em espaços públicos e domiciliares, potencializando as ações de cuidado da equipe que compartilha o plano terapêutico.

Os Acompanhantes Terapêuticos, preocupados com o manejo do vínculo e da escuta realizaram esforços para construir um saber que respondesse as particularidades do AT, que além de criar uma relação potencialmente terapêutica com o sujeito acompanhado, explora com ele os espaços que fazem parte do seu território de vida. ${ }^{(9)}$

A oferta do AT dá espaço para que o sujeito acompanhado possa dizer e elaborar simbolicamente sobre a singularidade que se manifesta, por exemplo, no delírio ou em outros fenômenos produzidos nos transtornos mentais. Oportunidade em que a atenção se volta para o que o sujeito faz enquanto interage com o meio e não apenas no que diz. ${ }^{(9)}$

Entre as tecnologias de cuidado desenvolvidas através da itinerância, também se destaca o Consultório de Rua como "uma iniciativa de atenção à saúde de pessoas que vivem em situação de rua, expostas ao uso de substâncias psicoativas"..(10:14) De acordo com Londero, Ceccim e Bilibio( ${ }^{(8)}$ a desisntitucionalização pouco abordou a questão da saúde da população em situação de rua, e na expectativa de atender a estas pessoas, o Consultório de Rua (CR) foi criado como um dispositivo terapêutico específico, que serviria para preencher esta lacuna no campo das políticas de saúde.

O CR surge, também, para atender as pessoas que não acessam os serviços de saúde específicos para usuários de substâncias psicoativas, até mesmo porque em muitos destes a abstinência se constitui como uma imposição. Com inspiração nas visitas realizadas pelo Dr. Antônio Nery Filho à sede do Médicos do Mundo, em Paris, foi criado em 1995 em Salvador/BA, a primeira equipe do projeto a ir à rua com o objetivo de oferecer assistência à saúde, para a população cuja situação associa a vulnerabilidade social e o uso de substâncias psicoativas. ${ }^{(10)}$

Em 2012, com a passagem do Consultório de Rua, que fizera parte Política Nacional de Saúde Mental, para a Política Nacional de Atenção Básica, esta prática passa a ser chamada de Consultório na Rua e acaba por se destinar a atender aos interesses do governo em prevenir o consumo e a dependência de drogas. ${ }^{(8)}$

Na prática do Consultório na Rua, o vínculo é o que permite a chegada de ações de promoção de saúde como "orientações sobre autocuidado, a Redução de Danos e a prevenção de doenças contagiosas" (pg.15), em uma perspectiva ampliada. Compreende-se por Redução de Danos as ações que visam transmitir métodos que buscam minimizar os riscos atrelados ao uso de substâncias, sem que seja necessário suspendê-lo. ${ }^{(4,10)}$ Esta prática representa uma alternativa ao paradigma da abstinência, ligado a políticas de repressão e ao proibicionismo, fazendo com que ela não seja a única opção de tratamento. ${ }^{(4)}$

$\mathrm{Na}$ política de humanização, o vínculo com os usuários aparece como um padrão na atenção em saúde, na forma de valorização dos desejos, interesses e especificidades dos usuários, entendendo que quando mobilizados, os usuários são capazes de protagonizar o tratamento e transformar a si próprios. ${ }^{\left({ }^{8}\right)}$ Para Londero, Ceccim e Bilibio ${ }^{(8)}$ é necessário que haja abertura para fazer um caminho de cuidado junto ao usuário, valorizando o seu saber sobre si.

No Guia do Projeto Consultório de Rua, destaca-se a proposta de "olhares cruzados", forma como os profissionais realizadores desta prática devem desenvolver seu trabalho. ${ }^{(9)}$ Existe o dever de destituir-se do olhar da sua técnica para enxergar a rua com o olhar do outro, ou seja, os olhares e as leituras devem se transversalizar dentro da equipe para 
que a interdisciplinaridade aconteça e fora dela para que haja vínculo com os usuários. (9) Para Londero, Ceccim e Bilibio ${ }^{(8)}$ é necessário que os CR's se deixem afetar de algum modo para que o contato se faça de maneira criativa e aberta a construção de um cuidado individual.

Um ponto de convergência entre Consultório na Rua e a prática do AT é a valorização do acaso. Ele surge no CR como aquilo que por não ser esperado ou planejado, se apresenta nas ruas de forma mais intensa, "o medo da polícia e da chuva". (8:5) O próprio contexto sem abrigo para o sol ou a chuva propiciam experiências mais vivas de contato. No Acompanhamento Terapêutico o inusitado pode gerar conflitos e desencadear delírios e alucinações, nesse sentido, oferecer a escuta levaria o sujeito a dizer sobre aquilo que lhe ocorre em ato, oportunizando chances para a criação de novas respostas à crise. ${ }^{(9)}$ Incluir o inesperado é uma forma de cuidado comum às práticas itinerantes $\mathrm{e}$ ainda que as surpresas estejam postas para qualquer profissional de saúde, nas ruas elas surgem de forma ainda mais abundantes.

Ao pensar que além do deslocamento que se realiza com os usuários no seu território, o movimento de ir ao seu encontro também se constitui uma prática itinerante, deve-se entender que este modelo poderia direcionar para a realização do movimento no âmbito estritamente físico, o que geraria uma ampliação da cobertura do espaço que se pretende atuar sem que ocorra, necessariamente, mudanças nas práticas voltadas exclusivamente para a prevenção e supressão de sintomas. ${ }^{(3)}$

Utilizado sem as devidas considerações, o contato com o território dos usuários fica restrito ao diagnóstico, classificação e intervenção sobre doenças, sem que se possa articular as demandas aos aspectos subjetivos e territoriais relacionado. ${ }^{(3)}$ Dentre as práticas itinerantes, o trabalho dos Agentes Comunitários de Saúde (ACS's) é o que mais facilmente poderia se tornar um método restrito de cuidado, mas através de uma execução advertida ele seria capaz de gerar "crítica ao modelo tradicional de atenção à saúde, em relação ao seu viés fragmentado e reducionista por ter a doença como objetivo exclusivo de intervenção". (3:38)

$\mathrm{Na}$ Política Nacional de Atenção Básica (2012) são atribuídas funções aos ACS's, entre elas: cadastrar, orientar, acompanhar por meio de visitas domiciliares a famílias e usuários de um determinado território (microárea); facilitar a integração entre a equipe da unidade de saúde e os usuários; estabelecer ações de promoção da saúde, prevenção das doenças e vigilância à saúde, através de visitas domiciliares e de ações educativas nos domicílios e na comunidade. ${ }^{(12)}$

Para além do instituído, os ACS's podem alterar o que está posto e se colocar à disposição de atender os pacientes egressos de espaços manicomiais através do acompanhamento, desta vez em um território de vida que é comum a ambos, ação que não é preconizada em suas atribuições. Os ACS's além de realizarem estratégias do Programa Saúde da Família, estão sendo convocados a realizar ações de Saúde Mental para o exercício do cuidado de quem faz uso de drogas ou possui algum transtorno mental. ${ }^{(4)}$

Assim como as outras práticas itinerantes destacadas, o trabalho dos ACS's articula os princípios do SUS de integralidade, universalidade e equidade para o alcance do que foi preconizado na Reforma Sanitária. Vinculam a isso ideias de racionalização de gastos que podem gerar como efeito o empobrecimento desta prática e um maior monitoramento da vida e do território. O uso de protocolos e ações previamente planejadas tornam esta prática a mais burocratizada das práxis itinerantes aqui destacadas, portanto, com mais hierarquização de saberes e barreiras para criação de um caminho conjunto de cuidado. (4) É importante ressaltar que os ACS's têm metas a cumprir e respondem a um supervisor enfermeiro, e quanto maior a pressão sobre este trabalhador, maior o risco de superficialidade em seu exercício.

A precaução com hierarquização de saberes e funções, dentro e fora das equipes de saúde, surge no trabalho dos ACS's como uma forma de humanizar e preservar o vínculo entre usuários e traba- 
Ihadores. A abertura para o diálogo é o que possibilita a construção de um território de cuidado, do mesmo modo como acontece com a prática do Acompanhamento Terapêutico e do Consultório na Rua, que utilizam o vínculo como ferramenta para a promoção de saúde e no caso do $C R$, também de atenção aos direitos sociais.

Assim como para a prática do Consultório na Rua e para o desenvolvimento do trabalho dos ACS's, o vínculo desenvolvido entre o AT e o usuário além de depender da sua relação com o seu saber, depende de uma rede que se constrói incluindo seus familiares e a equipe multidisciplinar, responsáveis pela construção coletiva de um cuidado singular. Para que também este saber não se torne hierarquizado, o AT tem o dever de recorrer a discussões sobre o andamento do caso de quem acompanha. $(9)$

O cuidado é outro ponto de convergência entre as práticas itinerantes, pensado como uma atitude que deve permear as estratégias de saúde e a formação do vínculo entre os profissionais e os usuários. Ayres ${ }^{(13)}$ refere que o cuidado deve ser entendido como postura norteadora das práticas em saúde, sendo que este deve sobrepor a expectativa de ter um domínio técnico sobre o adoecimento. Cuidar deve favorecer a intersubjetividade e fazer com que o encontro entre profissionais e usuários gere transformações e faça com que o sujeito possa desenvolver também o cuidado de si.

Para Ayres, (13:70) "curar, tratar, controlar tornam-se posturas limitadas", visto que tomam o sujeito como objeto das ações de saúde, enquanto a relação de cuidado inclui as competências técnicas e as ultrapassa ao considerar os projetos vida e de felicidade, a confiança e a responsabilidade como parte da atenção humanizada e de uma visão mais ampliada sobre a saúde. ${ }^{(13,14)}$

O movimento é outro item importante a ser destacado ao tratar da itinerância. As práticas itinerantes têm no território o espaço para a execução de diferentes movimentos, seja no plano espacial onde expõe os agentes às surpresas do caminho, ou no plano subjetivo ao deslocarem trabalhadores e usuários de posições cristalizadas que são abaladas pela complexidade de um território de vida. ${ }^{(4)}$ Do trabalhador se espera um certo deslocamento do seu lugar de detentor de saber e dos usuários um movimento que o faça se descolar das rotulações e do lugar de dependência, ora da família, ora das instituições.

Nenhuma das práticas itinerantes alcançaria o seu potencial de cuidado se tivesse como objetivo o controle das diferenças. O ponto que preserva sua potência é o respeito pela singularidade, que passa a ser acolhida como manobra para a formação de vínculos que sejam capazes de sustentar práticas verdadeiramente transformadores. Restringindo as práticas à tentativa de extinguir os sintomas perde-se a possibilidade de construir um caminho original de cuidado, passando a reproduzir a lógica manicomial, quando mesmo estando fora dos muros dos hospitais, impusesse aos usuários uma mesma forma de domínio sobre suas vidas.

\subsection{REPERCUSSÕES E ARTICULAÇÕES ENTRE AS PRÁTICAS ITINERANTES E AS POLÍTICAS DE SAÚDE}

O deslocamento no território em si não basta para atingir o potencial que essas práticas têm de abrir novos caminhos de cuidado, através de intervenções terapêuticas que indiquem a construção de novas respostas a situações de crise. ${ }^{(3)}$

A itinerância responde à demanda pela criação de novas formas de intervenção em saúde mental, que possam atender à necessidade dos usuários de se integrar socialmente, visto que tem o potencial de mantê-los ou reinseri-los em seus meios. Desse modo, além de gerar ganhos a autonomia dos usuários, que podem participar da criação dos seus roteiros e manter suas atividades de rotina, a itinerância é capaz de promover o deslocamento de posições cristalizadas, expondo o usuário e o acompanhante a ambientes e situações que podem ser diferentes daquelas que costumam vivenciar. ${ }^{(3)}$ 
As práticas itinerantes repercutem na ampliação de territórios, através do contato com elementos do cotidiano dos usuários, extraindo deles uma matéria-prima para a produção de novas formas de ver o que está posto. Abre a possibilidade de descolar o usuário daquele familiar que toma para si o controle de sua vida e imprime sobre ela o seu ritmo, dando margem à geração de uma postura crítica que daria espaço para o surgimento de movimentos genuínos. Assim como busca garantir que, também esse processo de diferenciação, não seja gerador de abismos entre o usuário e sua família. (4)

Através das práticas itinerantes, o território passa a ser entendido como um campo de construção de uma forma singular de cuidado, fazendo existir fora dos espaços comuns de assistência, dispositivos que estão articulados aos princípios do SUS, ao processo da Reforma Psiquiátrica e ao desejo dos usuários de viver socialmente integrados, fora dos espaços de internação. $(4,3)$

A lei 10.216 (2001) que "dispõe sobre a proteção e os direitos das pessoas portadoras de transtornos mentais e redireciona o modelo assistencial em saúde mental" traz a indicação de esforços que devem ser feitos em favor da desinstitucionalização da loucura, reconhecendo a importância de formas de atenção em saúde mental que, assim como as práticas de cuidado itinerantes, visem garantir a socialização e a permanência dos usuários em seus territórios de vida. O Art. $4^{\circ}$ regulamenta que "a internação, em qualquer de suas modalidades, só será indicada quando os recursos extra hospitalares se mostrarem insuficientes". ${ }^{(15)}$ O parágrafo primeiro deste artigo determina que o tratamento visará, como finalidade permanente, a reinserção social do paciente em seu meio. ${ }^{(15)}$ Desse modo, as práticas itinerantes se constituiriam como um recurso para o cumprimento da lei ao lançar mão de estratégias para evitar a internação dos usuários e mantê-los em seus territórios.

A desinstitucionalização que, à primeira vista, representaria a recusa da internação como forma de tratamento, teria seu sentido ampliado ao ser tomada como uma atitude ética e política no tra- balho com os usuários e, também, como um método que poria de lado o repertório de códigos que podem gerar entraves ao processo de cuidado, ou seja, a desinstitucionalização subentende uma forma de trabalho que coloque em suspensão os estigmas e a fixação do sujeito as classificações diagnósticas. (4)

O trabalho com a itinerância deve ser sustentado por uma postura ética por parte dos profissionais envolvidos, que tem o dever de sempre pôr em questão os efeitos de suas práticas sobre os sujeitos, já que estas podem estar a serviço de um controle das diferenças, caso estejam restritas à sintomatologia. ${ }^{(3)}$

Os princípios do SUS de universalidade e equidade dizem respeito ao acesso à saúde, um direito social que deve ser assegurado através da criação de políticas públicas que ampliem a cobertura e a intensidade de ações voltadas para aqueles que são excluídos dos serviços de saúde. ${ }^{\left({ }^{(6)}\right)}$ Nesse sentido, as práticas itinerantes podem servir como forma de aplacar a desigualdade de assistência em saúde, através da aproximação com o território daqueles que não são assistidos por práticas de cuidado que permanecem institucionalizadas. ${ }^{(3)}$

A universalidade, outro princípio do Sistema Único de Saúde, pressupõe que as estratégias de saúde levem em conta a diversidade do território dos usuários e para fazê-la valer, as práticas itinerantes citadas neste estudo buscam atender às demandas de pessoas que, ordinariamente, não são assistidas pelos serviços comuns de atenção à saúde, como os moradores de rua, povos tradicionais como indígenas e quilombolas, povos nômades, pessoas egressas de internações psiquiátricas e usuários de drogas. ${ }^{(16,3)}$

Em mais uma aproximação com o princípio da universalidade, a lei 10.216 busca garantir que todas as pessoas com transtorno mental, independente do grau de gravidade ou tempo de evolução de seu quadro clínico, ou ainda dos seus recursos, sejam assistidas pelos serviços específicos destinados a este público. ${ }^{(15)}$ Nesta lei, também se evidencia a indicação para priorizar o tratamento em 
serviços comunitários de saúde mental, o que representa estar próximo ao território dos usuários.

Segundo a Política Nacional de Humanização, o campo da saúde vem passando por avanços que expandem os princípios de integralidade, equidade e universalidade, como, por exemplo, o crescente processo de descentralização da atenção e da gestão em saúde. Mas este campo também vivencia problemas relacionados à fragmentação e verticalização dos processos de trabalho, bem como a aparente deficiência em lidar com questões sociais e subjetivas nas práticas de saúde. ${ }^{(17)}$

A falta de inclusão dos trabalhadores e dos usuários nos processos de produção de saúde e a precarização do contato entre estes, se mostram contrários aos objetivos do SUS de garantir o direito à saúde para todos e impedem a formação de vínculo entre estes mesmos agentes. ${ }^{(18)}$ Notou-se uma atuação direcionada para a solução de queixas, onde a atenção se voltaria para as partes de um corpo adoecido sem que o sujeito e o processo de adoecimento sejam vistos como um todo, contrariando o princípio da integralidade que articula ações e serviços preventivos e curativos, individuais e coletivos para dar conta de todos os níveis de complexidade do processo de adoecimento.

A Política Nacional de Humanização da Atenção e da Gestão em Saúde (PNH) entende que a humanização é "ofertar atendimento de qualidade articulando os avanços tecnológicos com acolhimento, com melhoria dos ambientes de cuidado e das condições de trabalho dos trabalhos". ${ }^{17)}$ Desse modo é possível inferir que as práticas ligadas aos territórios de vida dos usuários são práticas humanizadoras, porque transformam espaços do cotidiano em ambientes de cuidado, ampliando o seu sentido e garantindo a permanência dos usuários.

A PNH preconiza em suas diretrizes a presença de dispositivos que ofereçam alternativas à hospitalização. ${ }^{(17)}$ Nesse sentido, as práticas de cuidado itinerantes se afinam a esta pretensão por se oferecerem como alternativa às internações em hospitais psiquiátricos e a outras práticas hospitalares que podem não atender aos interesses dos usuários.

\section{CONSIDERAÇÕES FINAIS}

As práticas itinerantes de cuidado em Saúde Mental são intervenções em saúde caracterizadas, sobretudo pelo deslocamento no território de vida dos usuários, ou seja, no lugar onde são mantidas relações de pertencimento. O Acompanhamento Terapêutico, o Consultório de Rua e o trabalho dos Agentes Comunitários de Saúde tornaram-se importantes tecnologias do cuidado, por terem o potencial de substituir práticas que envolvem a privação de liberdade. As práticas de cuidado itinerantes pretendem garantir a integralidade, universalidade e igualdade, princípios do Sistema Único de Saúde, bem como preservar a autonomia dos usuários evitando internações e a submissão a práticas cronificadoras.

O exercício das práticas itinerantes tem o potencial de gerar transformações no usuário e nas equipes de saúde. A estratégia da itinerância implica na modificação da relação terapêutica, que deve dar espaço para o afeto e para o saber do outro. As práticas de cuidado itinerantes repercutem como críticas aos modelos de cuidado existentes, dando visibilidade àqueles que não são contemplados nas estratégias tradicionais do SUS, problematizando as formas como as ações de saúde são realizadas e o modo como os serviços são organizados.

As práticas itinerantes ressoam conferindo ao território a categoria de espaço de cuidado, onde a hospitalização deixaria de ser o único recurso para usufruir dos serviços de saúde, tornando-se possível a construção de um modo singular de atenção que articularia os interesses da Reforma Psiquiátrica e o desejo dos usuários de permanecer fora dos espaços de internação.

\section{REFERÊNCIAS}

1. Lancetti A. Clínica peripatética. $9^{\mathrm{a}}$ ed. São Paulo: Hucitec; 2014.

2. Gil AC. Métodos e técnicas de pesquisa social. $5^{a}$ ed. São Paulo: Atlas;1999. 
3. Lemke RA, Silva RAN da. Um estudo sobre a itinerância como estratégia de cuidado no contexto das políticas públicas de saúde no Brasil. Physis. 2011; 21(3): 979-1004 [acesso em 10 fev. 2O15]. Disponível em: http://www.scielo.br/scielo.php?pid=SO1O3$73312011000300012 \&$ script=sci_arttext

4. Lemke RA. A itinerância e suas implicações na construção de um ethos do cuidado [dissertação]. Rio Grande do Sul: Universidade Federal do Rio Grande do Sul; 2009 [acesso em 10 fev. 2015]. Disponivel em: http://www.lume.ufrgs.br/ bitstream/handle/10183/17224/000711099. pdf? sequence $=1$

5. Amarante P. Saúde mental e atenção psicossocial. $3^{a}$ ed. Rio de Janeiro: Fiocruz; 2007.

6. Amarante P. Loucos pela vida. $6^{a}$ ed. Rio de Janeiro: Fiocruz; $2 \mathrm{Ol3}$.

7. Paiva CHA, Teixeira LA. Reforma Sanitária e a criação do Sistema Único de Saúde: notas sobre contextos e autores. Hist. cienc. saude-Manguinhos. 2014 [acesso em 12 set. 2015]:;1:15-35. Disponível em: http://www.scielo. $\mathrm{br} / \mathrm{sciel}$.php?script=sci_arttext\&pid=SO1O459702014000100015\&lng=en\&nrm=iso\&tlng $=\mathrm{pt}$

8. Lemke RA, Silva RAN. da. A busca ativa como princípio político das práticas de cuidado no território. Estud. pesqui. psicol. 2010 [acesso em 10 fev. 2015]; 10(1):281-295. Disponível em: http://www.revispsi.uerj.br/v1Onl/artigos/pdf/ vlOnla18.pdf

9. Reis Neto R de O; Pinto ACT, Oliveira LGA. Acompanhamento terapêutico: história, clínica e saber. Psicol cienc prof.; $2 \mathrm{Ol1}$ [acesso em $2 \mathrm{O}$ mar. 2015]; 31(1):30-39. Disponível em: http:// www.scielo.br/scielo.php?script=sci_arttext\&pid =S1414-98932011000100004

10. Nery Filho A. Guia do projeto Consultório de Rua. Brasília: SENAD; Salvador: CETAD; 2011.

11. Londero MFP, Ceccim RB, Bilibio FS. Consultório de/na rua: desafio para um cuidado em verso na saúde. Interface. 2014 [acesso em 20 mar.
2015]; 18(49):251-260 Disponível em: http:// www.scielo.br/scielo.php?script=sci_arttext\&pid =S1414-32832014000200251

12. Ministério da Saúde (BR). Política Nacional de Atenção Básica. Brasília: Ministério da Saúde; 2012 [acesso em 12 ago. 2015]. Disponível em: http://189.28.128.100/dab/docs/publicacoes/ geral/pnab.pdf

13. Ayres JR de CM. Sujeito, intersubjetividade e práticas de saúde. Ciênc saúde coletiva. 2001 [acesso em $2 \mathrm{O}$ out. 2O15] ;6(1):63-72. Disponível em: http://www.scielo.br/scielo.php?script=sci_art text\&pid=S1413-81232001000100005

14. Ayres JR de CM. O cuidado, os modos de ser (do) humano e as práticas de saúde. Saude soc. 2004 [acesso em 20 out. 2015];13(3):16-29. Disponível em: http:// www.scielo.br/scielo.php?pid=SO1O4$12902004000300003 \&$ script=sci_arttext

15. BRASIL. Presidência da República, Subchefia para Assuntos Jurídicos. Lei n. 10.216, de 6 de abril de 2001. Dispõe sobre a proteção e os direitos das pessoas portadoras de transtornos mentais e redireciona o modelo assistencial em saúde mental [Internet]. Brasília, DF; 2001 [acesso em 12 nov. 2015].

16. Disponível em: http://www.planalto.gov.br/ ccivil_O3/leis/LEIS_2OOI/L1O216.htm

17. Brasil. Presidência da República, Subchefia para Assuntos Jurídicos. Lei n. 8.080, de 19 de setembro de 1990. Dispõe sobre as condições para a promoção, proteção e recuperação da saúde, a organização e o funcionamento dos serviços correspondentes e dá outras providências [Internet]. Brasília, DF; 1990. [acesso em O5 jan. 2015]. Disponível em: http:// www.planalto.gov.br/ccivil_O3/Leis/L8080.htm

18. Ministério da Saúde (BR). HumanizaSUS. Política Nacional de Humanização: A humanização como eixo norteador das práticas de atenção e gestão em todas as instâncias do SUS. Brasília, DF: Ministério da Saúde; 2004 [acesso em 12 ago. 2015]. Disponível em: http://bvsms.saude. gov.br/bvs/publicacoes/humanizaSus.pdf 